\title{
As diferentes facetas da Penitência
}

The different facets of Penance

Las distintas facetas de la Penitencia

Les différentes facettes de la Pénitence

Elaine Cristine dos Santos Pereira Farrel|[1]

MEENS, Rob. Penance in Medieval Europe 600-1200. Cambridge: Cambridge University Press, 2014. 282 p.

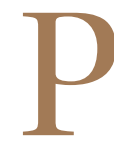

enitência é um tópico popular atualmente entre os medievalistas. Isso não é surpresa, já que penitência tem sido um aspecto importante da religiosidade Cristã desde a Antiguidade tardia e um tema presente na maioria dos gêneros literários medievais. Ao contrário, o que deveria estarrecer é a falta de interesse no tema.

Felizmente, vários pesquisadores distintos têm devotado atenção a esse assunto nas últimas décadas. A penitência tem sido investigada sob diferentes perspectivas como a sua teologia, mas, talvez, ainda mais importante, a sua prática $^{2}$. O recente interesse de acadêmicos na literatura penitencial está intrinsicamente relacionado a esse tema. Depois das publicações de John McNeill e Thomas Oakley nas décadas de 1920 e 1930, esse gênero foi relativamente negligenciado por algum tempo, até que nas décadas de 1970 e 1980, pesquisadores reavaliaram a importância dos penitenciais para os estudos históricos (McNeill, 1923; Oakley, 1923).

O reavivamento do interesse em arrependimento, confissão e penitência é concorrente com o crescimento da popularidade da história das mentalidades e história cultural, que trouxe para o seio dos debates históricos aspectos da vida que não eram frequentemente visitados por historiadores anteriormente (Meens, 1997, p.74; Vainfas, 1997, p.127-162). Ainda mais recente, o estudo da penitência tem sido reconectado ao campo da história do poder e ideias políticas, mas de uma forma diferenciada. A penitência tem sido investigada sob o ângulo da negociação de conflitos e disputas, um campo de estudo que tem ganhado atenção recentemente (Meens, 2014, p. 6, 10). A troca de ângulo e de

Resenha recebida em 26 de maio de 2015 e aprovada para publicação em 01 de junho de 2015.

[1]Professora do Departamento de História da Universidade de Utrecht e University College Dublin - Utrecht - Holanda. E-mail: elainepereirafarrell@gmail.com.

2Para uma revisão detalhada da historiografia, ver Meens (2008). 
perspectiva igualmente não deveria causar surpresa, visto que a maneira a qual os historiadores compreendem o poder e o estudam, também tem mudado.

Como Marcelo Cândido bem apresentou, "essa 'Nova História Política' não enxerga o poder apenas como uma forma de controle sobre homens ou sobre estruturas" (Silva, 2013, p. 101), mas esta também se ocupa das relações sociais e das relações entre pessoas e coisas, ou em outras palavras, como as pessoas se apropriam das coisas. A história do poder é hoje em dia feita em aproximação à história da cultura e da antropologia.

Penitência é um assunto que está relacionado a diversos aspectos da vida. Ela é relacionada à religião, e, portanto, à cultura, ao poder, pois está ligada a instituições e, algumas vezes, também à economia, pois, por exemplo, indivíduos são recomendados a cumprir penitência por roubo. Entretanto, foi no contexto dos estudos do conflito e com uma abordagem sociocultural que Rob Meens escreveu sobre penitência. Trabalhos anteriores, tais como The Penitential State da Mayke de Jong, já mesclaram história das religiões com política e demonstraram que penitência pode ser um instrumento útil na negociação de conflitos. A obra de Meens aborda principalmente esse aspecto da penitência, analisando a sua prática desde a Antiguidade tardia até o século XII, levando em consideração os distintos centros e contextos da produção penitencial.

\section{A história do poder é hoje em dia feita em aproximação à história da cultura e da antropologia}

A introdução do livro de Meens familiariza o leitor com os principais debates sobre a prática da penitência e argumenta pela centralidade da prática da confissão e penitência à natureza da religiosidade medieval (Meens, 2014, p. 1-11). O capítulo dois inicia na virada do século VI. Este evidencia que importantes escritores religiosos medievais contribuíram para gerar a ideia de que penitência é um instrumento essencial para a expiação de pecados. Indivíduos como João Cassiano, Tertuliano, Dionísio Exíguo e Sozomeno, dentre outros, foram agentes centrais nesse processo (Meens, 2014, p. 15-25). Meens também demonstra que a Gália no século VI não era uma terra infértil para penitência; ao contrário, pecado era considerado um problema grave e a importância da penitência enfrentada com seriedade nos concílios gauleses (Meens, 2014, p. 26-34).

A transição entre os capítulos dois e três levanta um dos argumentos centrais do livro: o fato de que não há diferenças essenciais entre os modos gaulês e irlandês de praticar penitência. Isso contribui para desconstruir um argumento que foi mantido por várias décadas, o de que o Cristianismo irlandês desenvolveu uma forma de penitência privada, que estaria oposta à penitência pública.

Todos os pesquisadores desenvolvendo a dita "nova história da penitência" como Meens, Jong e Sarah Hamilton, têm argumentado que o conceito de penitência secreta não existia na Alta Idade Média, e, que é, portanto, uma construção historiográfica (Hamilton, 2001, p. 3-25; Jong, 1997, p. 894-902). 
É um fato que o gênero de livros penitenciais é produto do mundo insular do século VI, mas as formas de expiar os pecados e praticar penitência descritas nestes são bastante próximas às praticadas na Gália do século VI ou pelos pais da Igreja (Meens, 2014, p. 38-69). Nesse capítulo, Meens apresentou o argumento de que os cânones penitenciais irlandeses indicam que os clérigos tiveram um papel importante na resolução de disputas, pois eles agiram como árbitros nos casos de "pecados sociais", tais como infrações sexuais e casos de violência. Frequentemente, a penitência em si em adição de pagamento em espécie, contrato matrimonial e retribuição em trabalho funcionaram como formas de satisfação às partes ofendidas em conflitos. Adicionalmente, ele enfatiza que as hagiografias podem contribuir para lançar luz sobre como a penitência teria, talvez, sido praticada na vida real. A Vitae Columbae, por exemplo, fornece histórias sobre pecadores que buscaram uma vida de penitência debaixo da instrução do São Columba em Iona, uma ilha nas margens da Escócia, mas que, naquela época, era conectada ao mundo irlandês. Os pecados sendo extirpados nessas anedotas ilustram circunstâncias mencionadas nos cânones penitenciais, tais como incesto e assassinato, por exemplo (Meens, 2014, p. 64-69).

\section{Todos os pesquisadores desenvolvendo a dita "nova história da penitência” têm argumentado que o conceito de penitência secreta não existia na Alta Idade Média}

O capítulo quarto trata do impacto da literatura penitencial insular no reino Franco e na Inglaterra. Columbano, o peregrino irlandês, contribuiu para popularizar o gênero no continente e a vida escrita sobre Fursa, outro peregrino irlandês que também discute penitência e a purgação de pecados (Meens, 2014, p. 70-81). Nesse mesmo capítulo, a íntima relação entre penitenciais e a literatura canônica é demonstrada. No mundo gaulês, a Collectio Vetus Gallica, ao mesmo tempo, foi influenciada e influenciou os livros penitenciais (Meens, 2014, p. 71, 96), e, no mundo anglo-saxão, a compilação dos ensinamentos de Teodoro de Canterbury reflete a simbiose entre esses dois gêneros (Meens, 2014, p. 88-96).

O capítulo seguinte está fortemente ligado ao anterior, visto que este discute penitência dentro do mundo carolíngio no contexto das ditas reformas. Wilibrordo e Bonifácio tiveram um importante papel nas reformas religiosas e nas empreitadas evangelísticas em processo na borda norte do reino. Portanto, Meens mantém que Wilibrordo e Bonifácio talvez estivessem envolvidos na produção de textos penitenciais, tais como o Paenitentiale Oxoniense II e o Excarpsus Cummeani, respectivamente. Bonifácio tinha fortes conexões com Corbie, de onde a Collectio Vetus Gallica é proveniente (Meens, 2014, p. 102-111). Meens destaca, ainda, que este foi um período de intensa produção de novos livros penitenciais e cópia de anteriores (Meens, 2014, p. 102, 139). De fato, é graças aos esforços carolíngios que a literatura penitencial sobreviveu. Meens argumenta que os compiladores 
dos penitenciais carolíngios expandiram consideravelmente o número de cânones que lidam exclusivamente com ofensas laicas, ampliando, assim, o caráter pastoral desses textos (Meens, 2014, p. 104).

No capítulo sexto, há uma mudança de cenário. Livros penitenciais estavam sendo produzidos também fora do mundo insular e carolíngio, em lugares como Espanha e Itália, mas como Meens frisa, as circunstancias políticas sob as quais a literatura penitencial floresceu nesses lugares eram diferentes (Meens, 2014, p. 164).

Três dos penitenciais espanhóis têm, dentre outras fontes, textos carolíngios como base, tais como o Excarpsus Cummeani. Entretanto, os penitenciais espanhóis são encontrados em manuscritos ricamente iluminados, indicando que eles não foram redigidos com fins pastorais (Meens, 2014, p. 164-70). Esses textos e sua relevância não foram exaustivamente estudados e ainda há penitenciais espanhóis que não foram estudados (Meens, 2014, p. 171-172). Além de explorar as abordagens espanholas e italianas quanto à penitência, Meens discute nesse capítulo o impacto dos trabalhos de Regino de Prum e Burcardo de Worms, e examina a prática da penitência entre as aristocracias (Meens, 2014, p. 141-154). Essa é outra parte chave do livro na qual exemplos de penitência funcionando como forma de instrumento de reconciliação de conflitos políticos são exibidos. Um dos exemplos fornecidos é o caso de Henry VI, a quem o papa Gregório VII havia excomungado. Devido à situação política instável da Itália, Gregório sentiu-se ameaçado pelos oponentes de Henry e decidiu restaurá-lo como membro da comunidade cristã através do cumprimento de penitência (Meens, 2014, p. 182-185).

O último capítulo lida com o século XII. Neste, o impacto dos trabalhos de indivíduos como Pedro Abelardo e Bartolomeu de Exeter são considerados (Meens, 2014, p. 119-213). Meens justifica bem a decisão de limitar seu estudo ao século XII, baseado em dois argumentos: o primeiro é o fato de que, após o século XII, os livros de penitência deixaram de ser copiados; segundo, porque o surgimento das escolas catedráticas e das universidades propiciou avanços nas discussões sobre os melhores mecanismos para corrigir comportamentos considerados pecaminosos e, como consequência desse processo, estudiosos buscaram distinguir entre direito canônico e literatura pastoral (Meens, 2014, p. 191-192). Pessoas como Burcardo de Worms, por exemplo, não pensava nesse tipo de distinção, portanto, esta foi uma mudança produzida no século XII (Meens, 2014, p. 191).

Penance in Medieval Europe de Meens é uma esperada contribuição ao campo. A obra traz um olhar novo sobre a penitência na Idade Média, através da análise desta sob o ângulo dos estudos de conflito. Ao mesmo tempo, este é um livro didático que dialoga e resume o conhecimento produzido nas últimas décadas sobre penitência tanto por Meens quanto por outros pesquisadores.

Essa obra é, portanto, uma leitura indispensável tanto para os especialistas em penitência quanto para os iniciantes nesse campo de estudo. A obra não apenas discute penitência nos livros penitenciais, mas em uma rica variedade de gêneros literários, em diferentes séculos e em contextos diversos da Europa 
Ocidental. Desse modo, a obra evidencia a multiplicidade de maneiras possíveis para se extirpar pecados na Idade Média e a centralidade da penitência nos discursos cristãos. Esse belo trabalho é fruto de anos de pesquisa no campo e de muita erudição.

\section{Referências bibliográficas}

HAMILTON, Sarah. The Practice of Penance, 900-1050. London: The Boydell Press, 2001.

JONG, Mayke de. What was Public about Public Penance? Paenitentia Publica and Justice in the Caroligian World, Settimane, vol. 44, n 2, p. 894-902, 1997.

MCNEILL, John T. The Celtic Penitentials and their Influence on Continental Christianity. Paris: Édourad Champion, 1923.

MEENS, Rob. Penance in Medieval Europe 600-1200. Cambridge: Cambridge University Press, 2014. MEENS, Rob. The Historiography of Early Medieval Penance, in Abigail Firey (ed.) A New History of Penance. Leiden and Boston: Bril, 2008.

OAKLEY, Thomas P. English Penitential Discipline and Anglo-Saxon Law and their Joint Influence. New York: Longmans, Green \& Co., 1923.

SILVA, Marcelo Cândido da. A Idade Média e a Nova História Política, Signum, v. 14, nº 1, p.91102, 2013.

VAINFAS, Ronaldo. História Das Mentalidades e História Cultural in Domínios da História: Ensaios de Teoria e Metodologia, Ciro F. Cardoso and Ronaldo Vainfas (eds.), Rio de Janeiro: Editora Campus, 1997. p.127-162.

VAINFAS, Ronaldo. História Das Mentalidades e História Cultural in CARDOSO, Ciro F.; VAINFAS, Ronaldo (eds.). Domínios da História: Ensaios de Teoria e Metodologia. Rio de Janeiro: Editora Campus, 1997. p.127-162. 